\title{
The "template" effect of the extra-framework content on zeolite compression: The case of yugawaralite
}

\section{EtTore Fois, ${ }^{1}$ Aldo Gamba, ${ }^{1}$ Gloria TABaCCHI, ${ }^{1}$ Rossella ArletTI, ${ }^{2}$ Simona QUartieri, $*, 3$ AND GIOVANNA VEZZALINI ${ }^{2}$}

\author{
'DSCA, Universita' dell'Insubria, via Lucini 3, I-22100 Como, Italy \\ ${ }^{2}$ Dipartimento di Scienze della Terra, Largo S. Eufemia, 19, I-41100 Modena, Italy \\ ${ }^{3}$ Dipartimento di Scienze della Terra, Salita Sperone 31, I-98166 Messina, S. Agata, Italy
}

\begin{abstract}
The microscopic behavior of the Ca-zeolite yugawaralite has been studied by ab initio molecular dynamics simulations adopting experimental cell parameters obtained at pressures up to $\sim 9 \mathrm{GPa}$. Pressure-induced volume contraction occurs via rotations of quasi-rigid $\mathrm{TO}_{4}$ tetrahedra that reduce the size of the channels in which the extra-framework species are located. Such rotations are governed by deformation of the coordination polyhedron of $\mathrm{Ca}$, which is made up of water and framework $\mathrm{O}$ atoms. Contraction of the $\mathrm{Ca}-\mathrm{H}_{2} \mathrm{O}$ distances is favored at moderate pressure; at higher pressure the shortening of $\mathrm{Ca}$-framework $\mathrm{O}$ atom distances becomes prevalent. The hydrogen bond network plays a fundamental role in the overall response to pressure. Our results indicate that the high- $P$-induced deformation of the framework structure is strictly correlated to the extra-framework species that act as "templates" in the compression process.
\end{abstract}

\section{INTRODUCTION}

Studies performed on the high-pressure (high- $P$ ) behavior of zeolites using non-penetrating pressure-transmitting media demonstrated that the compressibility of the zeolites studied to date is not only related to the framework density and topology, but is also affected by the type, amount, and location of the extraframework species (Arletti et al. 2003; Gatta et al. 2003a, and references cited therein). Moreover, the bulk modulus and the flexibility shown by framework microporous silicates show more complex behavior than that predicted by the "rigid-unit modes" theory (Dove et al. 1995, 2000; Hammonds et al. 1997, 1998).

Recent combined experimental-computational studies of the high- $P$ behavior of scolecite and bikitaite indicate that zeolitic water plays a relevant role in the overall response of the zeolite framework to pressure.

The high- $P$ deformation mechanism in scolecite (Ballone et al. 2002; Comodi et al. 2002) is based on the rotation of the tetrahedral chains parallel to $\mathbf{c}$ and the consequent compression of the channels. In addition, the formation of a strong water-water hydrogen bond, accompanied by the rotation of a water molecule of about $90^{\circ}$, was observed. Upon high-volume reduction, this inter-water bond remains the most stable and the best defined hydrogen bond in the system, while a few other transformations in the hydrogen bonding configuration were observed. This restructuring of the water-hydrogen bonding system was identified by the authors as the driving force for the transition undergone by scolecite under pressure and as a crucial feature affecting the channel geometry

\footnotetext{
*E-mail: simonaq@unimo.it
}

and the cell volume.

The effect of the extra-framework content on the compressibility of the fibrous zeolites scolecite and edingtonite was also discussed by Gatta et al. (2003a,b, 2004). The authors underlined the high bulk modulus values of the Ca- and Ba-polyhedron [73(5) and 72(5) GPa, respectively] with respect to the bulk modulii of the zeolite structures as a whole.

The peculiar aspect of bikitaite (Ferro et al. 2002), i.e., the presence of a "floating" one-dimensional water chain, is only partially maintained at high- $P$; the compression brings framework $\mathrm{O}$ atoms close enough to water hydrogen atoms to allow the formation of host-guest hydrogen bonds, without, however, destroying the one-dimensional chain. The volume decrease with pressure is achieved by rotation of the tetrahedral units. This rotation occurs in such a way as to fill spaces characterized by the lowest electronic densities, i.e., spaces with low extraframework species content.

The effects of different extra-framework cationic species on the compressibility of the synthetic zeolites Li-, NaCs-, and Cd-RHO in centric and acentric forms were studied by Lee et al. (2001). Cation-specific pressure responses were observed, made even more complex by sorption mechanisms due to the use of partially penetrating $P$-transmitting media. Moreover, an important role was attributed to the type of guest species (charge balancing cations or template molecules) in the reversibility of the pressure-induced amorphization of clathrasils (Tse et al. 1992) and of cation-exchanged LTA zeolites (Huang and Havenga 2001). In particular, it has been proposed that these guest species can act as "organizing centers" favoring reversibility of the amorphization process. 
In this study we present microscopic-level results, from computer simulations, on the high- $P$ behavior of yugawaralite. This microporous material was chosen for the following reasons: (1) its framework density (Baerlocher et al. 2001) is intermediate between that of zeolite A and bikitaite, the zeolites studied under high- $P$ with the lowest and highest framework density, respectively; (2) only one type of extra-framework cation (calcium) is present in the channels, and it has an ordered distribution; and (3) the distribution of the water molecules is, on the contrary, disordered at different crystallographic sites. Moreover, yugawaralite contains one partially occupied water site not coordinated to cations.

The specific aims of this investigation are the description and the interpretation at an atomistic level of: (1) the deformation mechanism of yugawaralite, (2) the two discontinuities found by Arletti et al. (2003) in the pressure-cell parameters dependences, and (3) the effects of the distribution of the water molecules on the response of this zeolite to applied pressure. To these aims, ab initio molecular dynamics computations, based on the experimental cell parameters determined under pressure, were performed.

\section{THE ZEOLITE YUGAWARALITE}

Yugawaralite is a Ca-zeolite whose framework topology (framework type YUG; Baerlocher et al. 2001; Armbruster and Gunter 2001) can be described by a pair of 5-membered rings sharing an edge (Fig. 1). These units share one branch, thus forming chains running parallel to $\mathbf{a}$; each chain is connected to the adjacent one, forming sheets in the a-c plane. The sheets are superposed to form channels parallel to [100] (Fig. 2) and [001] that are limited by 8 -rings. The topological symmetry $C 2 / m$ is reduced to the real symmetry $P c$ by the $(\mathrm{Si}, \mathrm{Al})$ ordering. There are one cation and five water extra-framework sites. Water molecule sites $\mathrm{W}_{2}$ and $\mathrm{W}_{3}$ are fully occupied, whereas $\mathrm{W}_{1}$ and $\mathrm{W}_{4}$ occupy two alternative positions $\left(\mathrm{W}_{1}\right.$ or $\mathrm{W}_{1 \mathrm{~A}}$ and $\mathrm{W}_{4}$ or $\mathrm{W}_{4 \mathrm{~A}}$ ) about 0.5 $\AA$ from each other. The water site $\mathrm{W}_{5}$ has an occupancy of $25 \%$. The Ca cation is coordinated to four framework $\mathrm{O}$ atoms and four water molecules (Kvick et al. 1986). The water molecule at the $\mathrm{W}_{5}$ site is the only one not coordinated to $\mathrm{Ca}$.

The cell parameters and stability of yugawaralite were determined by Arletti et al. (2003) via in situ synchrotron X-ray

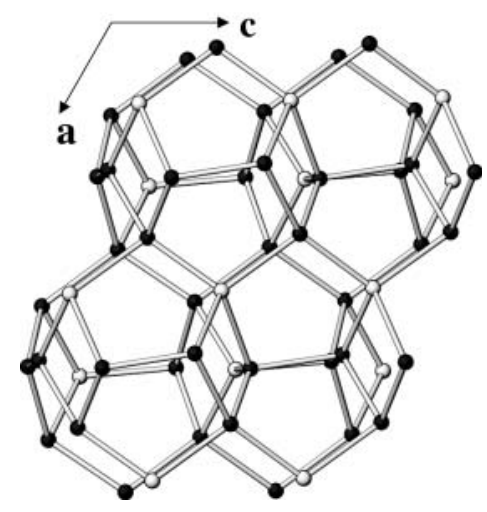

FIGURE 1. Stick-and-ball drawing of the yugawaralite framework along [010], showing the pairs of 5-membered rings sharing an edge. White circles $=\mathrm{Al}$; gray circles $=\mathrm{Si}$. powder diffraction from room pressure to $10 \mathrm{GPa}$ using a nonpenetrating $P$-transmitting medium. The structure is very stable up to the highest investigated pressures and no amorphization is observed in the studied $P$ range. Moreover, the features of the ambient pressure pattern are almost completely recovered upon decompression. The $a$ and $c$ cell parameters contract by about $7 \%$, while very minor variations affect the $b(2.4 \%)$ and $\beta(1.3 \%)$ parameters. All the cell parameters show two discontinuities, between 1.5 and $2 \mathrm{GPa}$ and between 3.9 and $5.3 \mathrm{GPa}$ (Fig. 3 in Arletti et al. 2003). The corresponding decrease in the compressibility values suggests a change in the response to pressure mechanism.

\section{COMPUTATIONAL METHOD AND SIMULATION MODELS}

Simulations were performed with the Car-Parrinello ab initio molecular dynamics (MD) technique (Car and Parrinello 1985) in the NVT ensemble with a fixed number of atoms and cell parameters (volume) and a fixed temperature of $298 \mathrm{~K}$ (Nosé 1984). From the experimental curves reported by Arletti et al. (2003) for cell parameters vs. pressure, we sampled values corresponding to some characteristic points close to the discontinuities and used them for the ab initio MD simulations. Reference simulations adopting the experimental cell parameters found at room pressure $\left(P_{\mathrm{amb}}\right)$ were performed as well. The values of the cell parameters, volumes, and corresponding experimental pressures
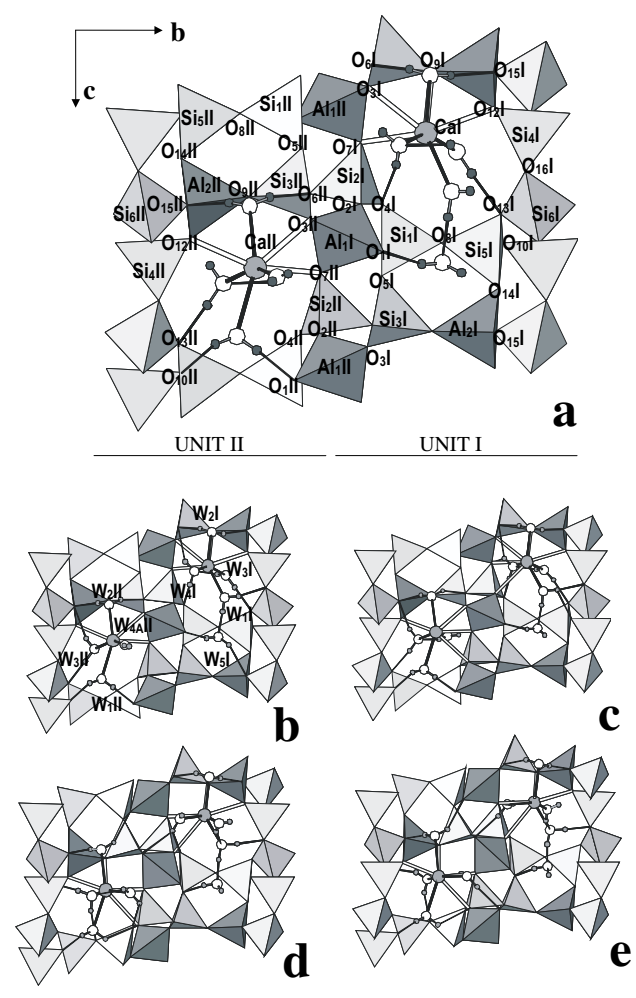

FIGURE 2. Projections of the yugawaralite structure, showing the 8ring channels along [100]. Roman symbols I and II, present in the atom labels, identify the atoms as belonging to UNIT I and II, respectively. Ca coordination distances $\leq 3.0 \AA$ and hydrogen bond distances $\leq 2.3$ $\AA$ are shown in the figures. (a) $P_{\text {amb }}$; (b) $1.5 \mathrm{GPa}$; (c) $3.9 \mathrm{GPa}$; (d) 6.3 $\mathrm{GPa}$; and (e) $8.8 \mathrm{GPa}$. 

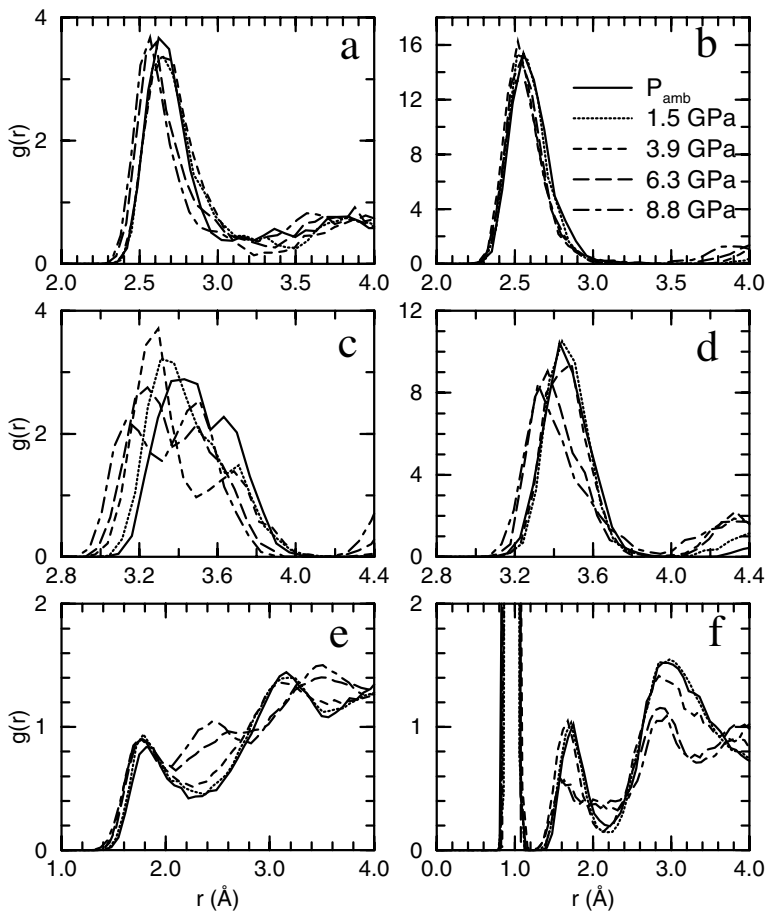

FIGURE 3. Extraframework atom radial distribution functions calculated from the five simulations. (a) $\mathrm{Ca}-\mathrm{O}_{\text {frame }}$; (b) $\mathrm{Ca}-\mathrm{O}_{\text {water }}$; (c) $\mathrm{Ca}-\mathrm{Si}$; (d) $\mathrm{Ca}-\mathrm{Al}$; (e) $\mathrm{H}-\mathrm{O}_{\text {frame}}$; and (f) $\mathrm{H}-\mathrm{O}_{\text {water }}$.

for the simulated systems are reported in Table 1 . The adopted stoichiometry for the simulation cell is $\mathrm{Ca}_{2}\left[\mathrm{Al}_{4} \mathrm{Si}_{12} \mathrm{O}_{32}\right] \cdot\left(\mathrm{H}_{2} \mathrm{O}\right)_{9}$ (YU9W from now on), which corresponds to the unit-cell content experimentally determined at $P_{\text {amb }}$ by Alberti et al. (1994).

In particular, the system contains one $\mathrm{Ca}$ atom and five $\mathrm{H}_{2} \mathrm{O}$ molecules in the first unit (UNIT I) and one $\mathrm{Ca}$ atom and four $\mathrm{H}_{2} \mathrm{O}$ molecules in the second (UNIT II) (Fig. 2). This choice corresponds to an overall occupancy at the $\mathrm{W}_{5}$ site of $50 \%$, larger than that experimentally determined $(25 \%)$ by Alberti et al. (1994). However, simulation of the precise experimental $\mathrm{W}_{5}$ site occupancy would have required the use of large and computationally demanding simulation cells. The water content of the simulation model was assumed to be constant in the studied pressure range, based on previous experimental studies of zeolites under pressure (Gillet et al. 1996; Comodi et al. 2001, 2002; Gatta et al. 2003, 2004), which report no sign of dehydration with compression.

The electronic structure calculations were performed via density functional theory (Kohn and Sham 1965) using gradient-corrected functional approximations for the exchange (Becke 1988) and correlation (Perdew 1986) energies. The electronic states were expanded in plane waves up to a cutoff energy of 60 Ry. Only

TABLE 1. Cell volumes, unit-cell parameters and total simulation time of the simulated systems

\begin{tabular}{lllcccc}
\hline$V\left(\AA^{3}\right)$ & $a(\AA)$ & $b(\AA)$ & $c(\AA)$ & $\beta(\circ)$ & $P(\mathrm{GPa})$ & Time $(\mathrm{ps})$ \\
\hline 881.7 & 6.7239 & 13.9952 & 10.0482 & 111.182 & $P_{\text {amb }}$ & 5.3 \\
851.4 & 6.6195 & 13.917 & 9.891 & 110.882 & 1.5 & 5.7 \\
805.5 & 6.463 & 13.873 & 9.581 & 110.32 & 3.9 & 5.8 \\
778.1 & 6.355 & 13.802 & 9.451 & 110.17 & 6.3 & 6.2 \\
755.9 & 6.264 & 13.708 & 9.364 & 109.94 & 8.8 & 5.1 \\
\hline
\end{tabular}

valence electrons were explicitly taken into account, and the ionelectron interactions were described by separable norm-conserving pseudo-potentials of the Kleinmann-Bylander form; $d$-nonlocality was adopted for the $\mathrm{Si}, \mathrm{Al}$, and $\mathrm{O}$ atoms, $p$-nonlocality for the $\mathrm{Ca}$ atoms, whereas a local norm-conserving pseudopotential was used for the $\mathrm{H}$ atoms (Troullier and Martins 1991; Kleinmann and Bylander 1982). The parameters used for integration of the equations of motion were a time step of $0.121 \mathrm{fs}$ and an electronic fictitious mass of 500 au. All simulations were performed with the CPMD code (Hutter et al. 1990-2001, 1997-2001). This computational scheme is essentially the same as that adopted in previous studies of the behavior of hydrated and dehydrated zeolites and other framework minerals at atmospheric temperature and pressure, high pressure, or high temperature (Fois et al. 2001; Ferro et al. 2002; Alberti et al. 2003; Ceriani et al. 2004).

\section{ATOMISTIC INTERPRETATION OF THE DEFORMATION MECHANISM}

\section{Average structures}

The calculated atomic positions, averaged over the trajectories and over the two units -with the exception of $\mathrm{W}_{4}$ and $\mathrm{W}_{5}$ (present only in UNIT I) and $\mathrm{W}_{4 \mathrm{~A}}$ (present only in UNIT II)- are reported in Table $2^{1}$.

Figures $2 \mathrm{a}-\mathrm{e}$ show projections of the yugawaralite structure along [100] obtained from the five simulations of theYU9W system, without averaging over the two units. This may be used to identify the atoms corresponding to the labels used in Tables 3b-6.

Calcium coordination polyhedron. In all the simulated systems, $\mathrm{Ca}$ is always coordinated to the same four water molecules $\left(\mathrm{W}_{1}, \mathrm{~W}_{2}, \mathrm{~W}_{3}, \mathrm{~W}_{4}\right)$. Water molecule $\mathrm{W}_{5}$ (occupancy $50 \%$ ) is never found coordinated to $\mathrm{Ca}$. However, the $\mathrm{Ca}$ coordination changes with pressure. In particular, while at $P_{\text {amb }}$ and $1.5 \mathrm{GPa}$ each Ca atom is coordinated to four framework $\mathrm{O}$ atoms $\left(\mathrm{O}_{3}, \mathrm{O}_{7}, \mathrm{O}_{9}, \mathrm{O}_{12}\right)$, at $3.9 \mathrm{GPa}$ a fifth framework oxygen $\left(\mathrm{O}_{2}\right)$ enters the Ca coordination shell. At $6.3 \mathrm{GPa} \mathrm{O}_{3}$ leaves the $\mathrm{Ca}$ coordination shell and the cation becomes, on average, eight coordinated again. Such a coordination is conserved at $8.8 \mathrm{GPa}$ as well (see Table $3 \mathrm{a}$ ). The $\mathrm{O}_{2} \leftrightarrow \mathrm{O}_{3}$ exchange may be understood by considering that both $\mathrm{O}_{2}$ and $\mathrm{O}_{3}$ belong to the tetrahedron centered on $\mathrm{Al}_{1}$, and that such a tetrahedron rotates as a function of pressure. Upon

${ }^{1}$ For Table 2 and Table 4, deposit item AM-04-002, please see the MSA website (see inside front cover of a recent issue for current url information) or contact the MSA business office.

TABLE 3A. Ca coordination distances calculated from the average coordinates reported in Table 2

\begin{tabular}{|c|c|c|c|c|c|}
\hline Distances $(\AA)$ & $P_{\text {amb }}$ & $1.5 \mathrm{GPa}$ & $3.9 \mathrm{GPa}$ & $6.3 \mathrm{GPa}$ & $8.8 \mathrm{GPa}$ \\
\hline $\mathrm{Ca}-\mathrm{O}_{2}$ & 3.387 & 3.157 & 2.916 & 2.930 & 2.842 \\
\hline $\mathrm{Ca}-\mathrm{O}_{3}$ & 2.704 & 2.693 & 2.698 & 3.096 & 3.263 \\
\hline $\mathrm{Ca}-\mathrm{O}_{7}$ & 2.691 & 2.719 & 2.752 & 2.608 & 2.595 \\
\hline $\mathrm{Ca}-\mathrm{O}_{9}$ & 2.889 & 2.884 & 2.857 & 2.640 & 2.597 \\
\hline $\mathrm{Ca}-\mathrm{O}_{12}$ & 2.691 & 2.687 & 2.680 & 2.632 & 2.605 \\
\hline $\mathrm{Ca}-\mathrm{OW}_{1}$ & 2.566 & 2.542 & 2.525 & 2.459 & 2.410 \\
\hline $\mathrm{Ca}-\mathrm{OW}_{2}$ & 2.709 & 2.699 & 2.670 & 2.673 & 2.717 \\
\hline $\mathrm{Ca}-\mathrm{OW}_{3}$ & 2.620 & 2.586 & 2.555 & 2.570 & 2.563 \\
\hline $\mathrm{Ca}-\mathrm{OW}_{4}$ & 2.649 & 2.616 & 2.579 & 2.611 & 2.643 \\
\hline
\end{tabular}


TABLE Зв. Ca coordination distances, in UNIT I and II, calculated from the instantaneous atomic positions along the MD trajectory

\begin{tabular}{|c|c|c|c|c|c|}
\hline Distances $(\AA)$ & $P_{\mathrm{amb}}$ & $1.5 \mathrm{GPa}$ & $3.9 \mathrm{GPa}$ & $6.3 \mathrm{GPa}$ & $8.8 \mathrm{GPa}$ \\
\hline $\mathrm{Ca} \mathrm{I-O_{2 } \mathrm { I }}$ & $3.453(0.205)$ & $3.200(0.193)$ & $2.955(0.161)$ & $2.951(0.170)$ & $2.924(0.163)$ \\
\hline $\mathrm{Ca} \mathrm{I}-\mathrm{O}_{3} \mathrm{I}$ & $2.735(0.163)$ & $2.702(0.107)$ & $2.706(0.110)$ & $3.001(0.240)$ & $3.116(0.163)$ \\
\hline 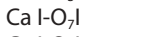 & $2.687(0.112)$ & $2.724(0.117)$ & $2.761(0.125)$ & $2.611(0.107)$ & $2.564(0.090)$ \\
\hline Ca I-OوI & $2.750(0.132)$ & $2.726(0.120)$ & $2.691(0.092)$ & $2.638(0.095)$ & $2.613(0.094)$ \\
\hline $\mathrm{Ca} I-\mathrm{O}_{12} \mathrm{I}$ & $2.750(0.115)$ & $2.763(0.124)$ & $2.776(0.135)$ & $2.690(0.108)$ & $2.661(0.101)$ \\
\hline Ca I-OW 1 & $2.539(0.085)$ & $2.535(0.089)$ & $2.507(0.079)$ & $2.498(0.069)$ & $2.490(0.071)$ \\
\hline $\mathrm{Ca} \mathrm{I-OW}{ }_{2}$ & $2.677(0.132)$ & $2.680(0.117)$ & $2.640(0.117)$ & $2.630(0.113)$ & $2.630(0.094)$ \\
\hline $\mathrm{Ca} \mathrm{I-OW} \mathrm{W}_{3}$ & $2.609(0.115)$ & $2.561(0.075)$ & $2.547(0.080)$ & $2.574(0.094)$ & $2.546(0.070)$ \\
\hline $\mathrm{Ca} \mathrm{I-OW} 4 \mathrm{I}$ & $2.737(0.153)$ & $2.694(0.109)$ & $2.655(0.115)$ & $2.676(0.112)$ & $2.703(0.144)$ \\
\hline Call- $\mathrm{O}_{2} \mathrm{II}$ & $3.321(0.175)$ & $3.134(0.211)$ & $2.902(0.178)$ & $2.928(0.173)$ & $2.782(0.144)$ \\
\hline Call- $\mathrm{O}_{3} \mathrm{II}$ & $2.714(0.113)$ & $2.705(0.107)$ & $2.713(0.134)$ & $3.213(0.272)$ & $3.433(0.180$ \\
\hline Call- $\mathrm{O}_{7} \mathrm{II}$ & $2.713(0.122)$ & $2.737(0.137)$ & $2.762(0.145)$ & $2.629(0.113)$ & $2.653(0.120)$ \\
\hline Call-O,Il & $3.051(0.236)$ & $3.061(0.223)$ & $3.141(0.540)$ & $2.666(0.137)$ & $2.606(0.082)$ \\
\hline Call-O ${ }_{12}$ II & $2.662(0.104)$ & $2.633(0.094)$ & $2.607(0.097)$ & $2.597(0.087)$ & $2.578(0.082)$ \\
\hline Call-OW 11 & $2.662(0.109)$ & $2.640(0.097)$ & $2.648(0.144)$ & $2.614(0.092)$ & $2.606(0.096)$ \\
\hline Call-OW & $2.744(0.149)$ & $2.747(0.158)$ & $2.730(0.141)$ & $2.739(0.136)$ & $2.830(0.218)$ \\
\hline Call-OW ${ }_{3} I I$ & $2.643(0.098)$ & $2.636(0.097)$ & $2.590(0.080)$ & $2.601(0.088)$ & $2.623(0.111)$ \\
\hline Call-OW $4 \mathrm{~A}$ Il & $2.602(0.130)$ & $2.577(0.084)$ & $2.547(0.094)$ & $2.597(0.096)$ & $2.616(0.095)$ \\
\hline
\end{tabular}

rotation, $\mathrm{O}_{2}$ moves to a coordination distance from $\mathrm{Ca}$, and at the same time, $\mathrm{O}_{3}$ starts to increase its separation from the $\mathrm{Ca}$ cation located in the neighboring unit (see Fig. 2e).

On the whole, in our simulations we detected two changes of coordination for the extra-framework Ca cation. The first, at $P>$ $1.5 \mathrm{GPa}$, is related to the approach of $\mathrm{O}_{2}$ to $\mathrm{Ca}$. The second, at $P$ $>3.9 \mathrm{GPa}$, is related to the loss of $\mathrm{O}_{3}$ from the Ca coordination shell. It is interesting to note that such modifications occur in correspondence to the experimentally detected discontinuities of the cell parameters with $P$, and suggest a fundamental role of extra-framework species in determining the yugawaralite response to pressure.

Another interesting point concerns the $\mathrm{Ca}-\mathrm{O}_{7}$ and $\mathrm{Ca}-\mathrm{O}_{12}$ bonds, which are always present and nearly aligned along $\mathbf{b}$ (see Fig. 2); these bonds, pointing toward opposite channel walls, brace the channel apertures, thus explaining the moderate contraction of the $b$ parameter with increasing pressure, as pointed out by Arletti et al. (2003). Let us now consider the $\mathrm{O}_{7}-\mathrm{O}_{12}$ and $\mathrm{O}_{14}-\mathrm{O}_{5}$ distances (both nearly parallel to $\mathbf{b}$ ) as a function of pressure. Up to $3.9 \mathrm{GPa}$ both distances are only slightly affected; the $\mathrm{O}_{7}-\mathrm{O}_{12}$ distance in particular is nearly constant (Fig. 2). At higher pressures, both distances contract significantly, however, the $\mathrm{O}_{14}-\mathrm{O}_{5}$ contraction $(\sim 18 \%)$ is much larger than the $\mathrm{O}_{7}-\mathrm{O}_{12}$ contraction $(\sim 3 \%)$. This finding is related to the supporting effect of the extra-framework cation in the 8-ring channel, as already discussed.

Further insight on the influence of $\mathrm{Ca}$ and of the other extraframework species on the compression mechanism of yugawaralite can be gained by inspecting the radial distribution functions of $\mathrm{Ca}$, with both framework and water $\mathrm{O}$ atoms as a function of the volume contraction (Figs. 3a-b). The position of the peak of the $\mathrm{Ca}-\mathrm{O}_{\text {water }}$ radial distribution function $g(r)$ (Fig. 3b) gradually shifts toward shorter distances in passing from $P_{\text {amb }}$ to $3.9 \mathrm{GPa}$, indicating a $P$-induced shortening of the coordination distances from the water $\mathrm{O}$ atoms. A pressure increase to $6.3 \mathrm{GPa}$ does not lead to a further decrease of the average $\mathrm{Ca}-\mathrm{O}_{\text {water }}$ distances. On the other hand, the position of the maximum in the $\mathrm{Ca}-\mathrm{O}_{\text {frame }} g(r)$ (Fig. 3a) remains nearly constant up to $3.9 \mathrm{GPa}$, whereas a further increase of pressure induces a significant shift of this maximum
TABLE 5. Hydrogen bond distances, in UNIT I e II, for the YU9W system, calculated from the instantaneous atomic positions sampled along the MD trajectory

\begin{tabular}{|c|c|c|c|c|c|c|}
\hline Molecule & Hydrogen bond (Å) & $P_{\text {amb }}$ & $1.5 \mathrm{GPa}$ & $3.9 \mathrm{GPa}$ & $6.3 \mathrm{GPa}$ & $8.8 \mathrm{GPa}$ \\
\hline $\mathrm{W}_{1} \mathrm{I}$ & $\mathrm{H}_{12} \mathrm{l}-\mathrm{O}_{16} \mathrm{I}$ & & 2.171 & 2.086 & 1.900 & 1.873 \\
\hline $\mathrm{W}_{1} \mathrm{I}$ & $\mathrm{H}_{12} \mathrm{I}-\mathrm{O}_{10} \mathrm{I}$ & & & 2.314 & & \\
\hline $\mathrm{W}_{1} \mathrm{I}$ & $\mathrm{H}_{11} \mathrm{I}-\mathrm{W}_{5} \mathrm{I}$ & 1.755 & 1.727 & 1.669 & 1.683 & 1.651 \\
\hline$W_{1} I I$ & $\mathrm{H}_{11} \mathrm{II}-\mathrm{O}_{1} \mathrm{II}$ & 2.076 & 2.076 & 2.027 & & \\
\hline$W_{1} I I$ & $\mathrm{H}_{11} \mathrm{II}-\mathrm{O}_{2} \mathrm{II}$ & & & & 2.224 & 2.259 \\
\hline$W_{1} I I$ & $\mathrm{H}_{12} \mathrm{II}-\mathrm{O}_{10} \mathrm{II}$ & 2.036 & 2.000 & 1.937 & 1.870 & 1.780 \\
\hline $\mathrm{W}_{2} \mathrm{I}$ & $\mathrm{H}_{21} \mathrm{I}-\mathrm{O}_{6} \mathrm{I}$ & 1.978 & 2.010 & 1.928 & 2.074 & 2.094 \\
\hline $\mathrm{W}_{2} \mathrm{I}$ & $\mathrm{H}_{22} \mathrm{I}-\mathrm{O}_{15} \mathrm{I}$ & 1.924 & 1.858 & 1.764 & 1.711 & 1.656 \\
\hline$W_{2} I I$ & $\mathrm{H}_{21} \mathrm{II}-\mathrm{O}_{1} \|$ & & & & 2.172 & 2.168 \\
\hline $\mathrm{W}_{2} \mathrm{II}$ & $\mathrm{H}_{21} \mathrm{II}-\mathrm{O}_{6} \mathrm{II}$ & 2.122 & 2.154 & 2.177 & 2.347 & 2.304 \\
\hline $\mathrm{W}_{2} \mathrm{II}$ & $\mathrm{H}_{22} \mathrm{II}-\mathrm{O}_{15} \mathrm{II}$ & 1.946 & 1.936 & 1.920 & 1.775 & 1.731 \\
\hline $\mathrm{W}_{3} \mathrm{l}$ & $\mathrm{H}_{32} \mathrm{I}-\mathrm{O}_{11} \mathrm{I}$ & & & & & 2.340 \\
\hline $\mathrm{W}_{3} \mathrm{I}$ & $\mathrm{H}_{32} \mathrm{I}-\mathrm{O}_{13} \mathrm{I}$ & 1.888 & 1.921 & 1.952 & & \\
\hline $\mathrm{W}_{3} \mathrm{I}$ & $\mathrm{H}_{31} I-W_{1} I$ & & & & 2.269 & 2.020 \\
\hline$W_{3} I$ & $\mathrm{H}_{31} \mathrm{I}-\mathrm{W}_{4} \mathrm{I}$ & & 1.862 & 1.901 & & \\
\hline $\mathrm{W}_{3} \mathrm{ll}$ & $\mathrm{H}_{32} \mathrm{II}-\mathrm{O}_{8} \mathrm{II}$ & & & & 1.889 & 1.942 \\
\hline $\mathrm{W}_{3} \mathrm{ll}$ & $\mathrm{H}_{31} \mathrm{II}-\mathrm{O}_{11} \mathrm{II}$ & & 2.385 & 2.352 & 2.151 & 2.252 \\
\hline $\mathrm{W}_{3} \mathrm{II}$ & $\mathrm{H}_{32} \mathrm{II}-\mathrm{O}_{13} \mathrm{II}$ & 1.779 & 1.808 & 1.875 & & \\
\hline $\mathrm{W}_{3} \mathrm{ll}$ & $\mathrm{H}_{31} \mathrm{II}-\mathrm{O}_{15} \mathrm{II}$ & & 2.336 & 2.099 & & 2.332 \\
\hline$W_{4} \mathrm{l}$ & $\mathrm{H}_{41} \mathrm{I}-\mathrm{O}_{3} \mathrm{II}$ & & & & 2.357 & 1.985 \\
\hline $\mathrm{W}_{4} \mathrm{I}$ & $\mathrm{H}_{41} \mathrm{I}-\mathrm{O}_{4} \mathrm{I}$ & 2.151 & 1.834 & 1.907 & 2.185 & 2.344 \\
\hline $\mathrm{W}_{4} \mathrm{I}$ & $\mathrm{H}_{42} \mathrm{I}-\mathrm{O}_{4} \mathrm{I}$ & & & & & 2.370 \\
\hline $\mathrm{W}_{4} \mathrm{I}$ & $\mathrm{H}_{42} \mathrm{I}-\mathrm{O}_{6} \mathrm{I}$ & & 2.261 & 2.240 & & \\
\hline $\mathrm{W}_{4} \mathrm{I}$ & $\mathrm{H}_{42} \mathrm{I}-\mathrm{O}_{7} \mathrm{I}$ & & & 2.210 & 2.363 & 2.373 \\
\hline $\mathrm{W}_{4 \mathrm{~A}} \mathrm{ll}$ & $\mathrm{H}_{42 \mathrm{~A}} \mathrm{Il}-\mathrm{O}_{3} \mathrm{I}$ & & & & 2.386 & 1.989 \\
\hline $\mathrm{W}_{4 \mathrm{~A}} \mathrm{ll}$ & $\mathrm{H}_{42 \mathrm{~A}} \mathrm{II}-\mathrm{O}_{4} \mathrm{II}$ & & & & 2.172 & 2.325 \\
\hline $\mathrm{W}_{4 \mathrm{~A}} \mathrm{ll}$ & $\mathrm{H}_{41 \mathrm{~A}} \mathrm{Il}-\mathrm{O}_{7} \mathrm{II}$ & & & & & 2.375 \\
\hline$W_{4 A} l l$ & $\mathrm{H}_{41 \mathrm{~A}} \mathrm{ll}-\mathrm{W}_{3} \mathrm{Il}$ & 2.235 & & 1.843 & 2.272 & \\
\hline$W_{5} I$ & $\mathrm{H}_{51} \mathrm{I}-\mathrm{O}_{1} \mathrm{I}$ & 1.863 & 1.847 & 2.042 & 2.376 & \\
\hline $\mathrm{W}_{5} \mathrm{I}$ & $\mathrm{H}_{51} \mathrm{I}-\mathrm{O}_{5} \mathrm{I}$ & & & & 2.309 & 1.810 \\
\hline $\mathrm{W}_{5} \mathrm{I}$ & $\mathrm{H}_{52} \mathrm{I}-\mathrm{O}_{15} \mathrm{I}$ & & 2.317 & & & \\
\hline $\mathrm{W}_{5} \mathrm{I}$ & $\mathrm{H}_{52} \mathrm{I}-\mathrm{W}_{2} \mathrm{I}$ & & & & & 2.359 \\
\hline
\end{tabular}

toward shorter distances. These results indicate that moderate pressures (1.5-3.9 GPa) primarily affect the water coordination distances from $\mathrm{Ca}$. In this range the $\mathrm{Ca}$ coordination polyhedron undergoes, therefore, the energetically cheapest modifications, i.e., shortening of the distances from the more mobile water molecules. On the other hand, at higher pressures, contraction of the $\mathrm{Ca}-\mathrm{O}_{\text {frame }}$ distances becomes energetically more favorable than a further decrease of the $\mathrm{Ca}-\mathrm{O}_{\text {water }}$ ones. 
Framework. The average tetrahedral volume decrease calculated from our simulations amounts to about $3 \%$, a small contraction with respect to the $15 \%$ cell volume change experimentally determined in the range $P_{\text {amb }}$ to $8.8 \mathrm{GPa}$. This finding, which is in line with the high- $P$ behavior of other silicates, further supports the idea that $\mathrm{TO}_{4}$ tetrahedra behave as quasi-rigid bodies; rigid rotations are energetically favored rather than T-O distance contractions under applied pressure, as predicted by the RUM theory (Dove et al. 1995; Hammonds et al. 1997, 1998).

The $\mathrm{O}_{\text {frame }}-\mathrm{O}_{\text {frame }} g(r)$, shown in Fig. 4a, does not vary significantly with pressure; both the position and the shape of the first peak are nearly constant up to the highest investigated pressure. This finding is not surprising because the position of the first peak of the $\mathrm{O}_{\text {frame }}-\mathrm{O}_{\text {frame }} g(r)$ is related to the quasi-rigidity of the $\mathrm{TO}_{4}$ tetrahedra and, therefore, to the value of the O-T-O angles, which are always found to be very close to the ideal tetrahedral value of $109.4^{\circ}$, and to the T-O distances. The $\mathrm{Si}-\mathrm{O}_{\text {frame }}$ and Al- $\mathrm{O}_{\text {frame }} g(r)$ are shown in Figures $4 \mathrm{~b}-\mathrm{c}$. In both cases the position of the first maximum, corresponding to the T-O tetrahedral bond distances, is, as expected, nearly constant. Remarkably, the position of the second peak, which is related to the distance between the T and $\mathrm{O}$ atoms of the neighboring tetrahedral units, significantly shifts toward shorter distances with increasing pressure. This confirms our belief that the applied pressure mainly affects the $\mathrm{T}-\mathrm{O}-\mathrm{T}$ angles by the energetically cheaper rigid rotations of the tetrahedral units; indeed, the contraction of the average T-O-T angle, reported in Table $4^{1}$, amounts to $\sim 9^{\circ}$ in passing from $P_{\text {amb }}$ to $8.8 \mathrm{GPa}$. In particular, all $\mathrm{Si}-\mathrm{O}-\mathrm{Si}$ angles decrease with $P$, whereas the Al-O-Si angles show both positive and negative variations. Moreover, the behavior of the $\mathrm{Si}-\mathrm{O}_{\text {frame }}$ (Fig. 4b)
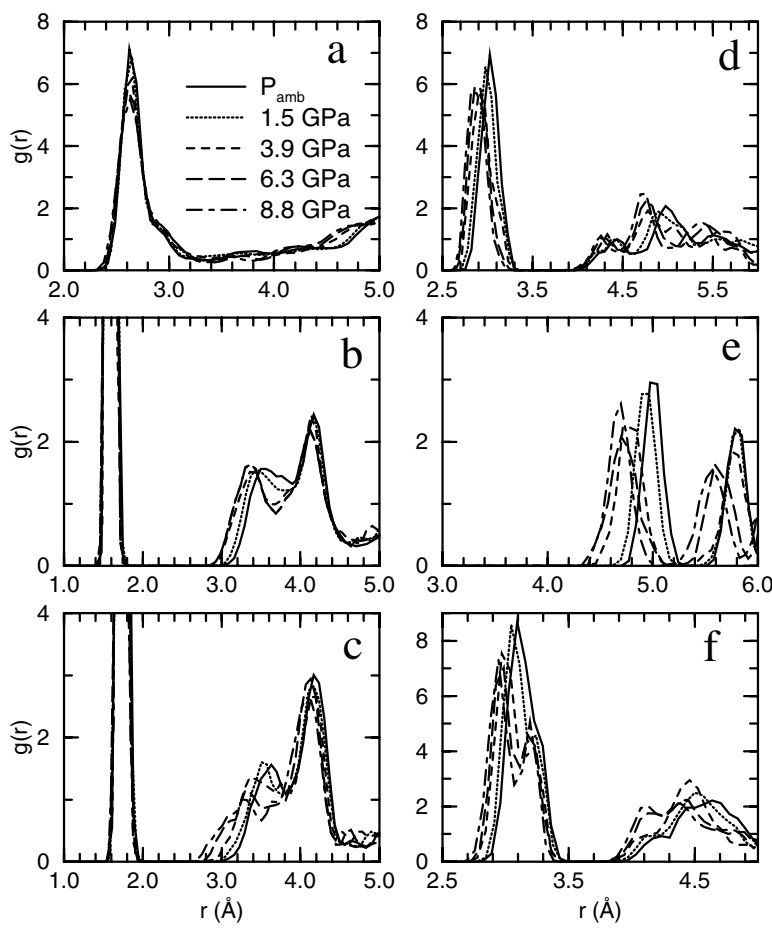

FIGURE 4. Framework atom radial distribution functions calculated from the five simulations. (a) $\mathrm{O}_{\text {frame }}-\mathrm{O}_{\text {frame }} ;$ (b) $\mathrm{Si}-\mathrm{O}_{\text {frame }} ;$ (c) $\mathrm{Al}-\mathrm{O}_{\text {frame }} ;$ (d) $\mathrm{Si}-\mathrm{Si}$; (e) Al-Al; and (f) Al-Si. and Al- $\mathrm{O}_{\text {frame }} g(r)$ curves (Fig. $4 \mathrm{c}$ ) is rather different at $P \geq 6.3$ $\mathrm{GPa}$. The $\mathrm{Si}-\mathrm{O}_{\text {frame }} g(r)$ does not change significantly, whereas a new shoulder appears at $r \approx 3 \AA$ in the Al- $\mathrm{O}_{\text {frame }}$ one. Such a behavior suggests that, under high pressure, the deformation of the framework occurs preferentially around the Al tetrahedra. On the basis of these findings it may be argued that the second discontinuity in the $V / P$ curve (Arletti et al. 2003), which we have already attributed to a change of $\mathrm{Ca}$ coordination, is also related to the response of the $\mathrm{AlO}_{4}$ tetrahedra. This is fully consistent with the above findings, recalling that both $\mathrm{O}_{2}$ and $\mathrm{O}_{3}$ framework $\mathrm{O}$ atoms, involved in the $\mathrm{Ca}$ coordination change, belong to an Al tetrahedron.

An important effect of pressure on the yugawaralite framework is the corrugation undergone by the chains of tetrahedra running parallel to $\mathbf{c}$, which is shown in Figure 2. This can be quantitatively described by the T-T distance distributions. The first peak of the Si-Si and Al-Al $g(r)$ curves (Figs. 4d-e) is unimodal at all the investigated pressures. However, in passing from $P_{\text {amb }}$ to $8.8 \mathrm{GPa}$ the $P$-induced shift of the first peak position in the $\mathrm{Al}-\mathrm{Al} g(r)$ is almost twice as large as in the $\mathrm{Si}-\mathrm{Si}$ one $(0.35$ vs. $0.20 \AA$ ). The Al-Si $g(r)$ values, shown in Figure 4f, highlight another interesting feature: the $g(r)$ at $P_{\mathrm{amb}}$ shows an unique peak centered at about $3.1 \AA$, with increasing pressure this peak splits, and above $6.3 \mathrm{GPa}$ the distribution is clearly bimodal (with two maxima at $\sim 2.95$ and $\sim 3.2 \AA$ ). This indicates that, at conditions far from $P_{\mathrm{amb}}$, the yugawaralite structure is characterized by two distinct groups of $\mathrm{Si}-\mathrm{Al}$ distances. Calculation of the individual $\mathrm{Al}_{1}-\mathrm{Si}$ and $\mathrm{Al}_{2}-\mathrm{Si} g(r)$ values showed that the distances are found at $\sim 2.95 \AA$, thus confirming the $P$-induced corrugation of the $\mathrm{Al}_{1}-\mathrm{Si}_{2}$ tetrahedral chain running along $\mathbf{c}$. Conversely, the peak

TABLE 6. Average geometry of the water molecules, in UNIT I and II, calculated from the instantaneous atomic positions sampled along the MD trajectory

\begin{tabular}{|c|c|c|c|c|c|c|}
\hline Molecule & $d 1(\AA ̊)$ & $d 2(\AA)$ & $\theta\left({ }^{\circ}\right)$ & $d 1(\AA ̊)$ & $d 2(\AA ̊)$ & $\theta\left({ }^{\circ}\right)$ \\
\hline & & $P_{\text {amb }}$ & & & $1.5 \mathrm{GPa}$ & \\
\hline$W_{1} I$ & 1.004 & 0.983 & 103.4 & 1.007 & 0.981 & 103.4 \\
\hline$W_{1} I I$ & 0.994 & 0.989 & 103.2 & 0.993 & 0.989 & 103.6 \\
\hline$W_{2} I$ & 0.989 & 0.994 & 103.5 & 0.988 & 0.995 & 103.8 \\
\hline $\mathrm{W}_{2} \mathrm{II}$ & 0.986 & 0.990 & 103.1 & 0.986 & 0.991 & 103.3 \\
\hline$W_{3} I$ & 0.990 & 0.991 & 106.3 & 0.996 & 0.986 & 107.2 \\
\hline $\mathrm{W}_{3} \mathrm{II}$ & 0.986 & 1.000 & 105.2 & 0.988 & 0.997 & 104.9 \\
\hline$W_{4} \mathrm{I}$ & 0.992 & 0.988 & 103.4 & 0.993 & 0.986 & 103.0 \\
\hline $\mathrm{W}_{4 \mathrm{~A}} \mathrm{II}$ & 0.996 & 0.986 & 103.8 & 0.985 & 0.989 & 103.6 \\
\hline \multirow[t]{2}{*}{$W_{5} \mathrm{I}$} & 0.997 & 0.983 & 102.9 & 0.998 & 0.984 & 103.2 \\
\hline & & $3.9 \mathrm{GPa}$ & & & $6.3 \mathrm{GPa}$ & \\
\hline$W_{1} I$ & 1.020 & 0.984 & 103.3 & 1.011 & 0.988 & 101.7 \\
\hline$W_{1} \|$ & 0.994 & 0.991 & 103.2 & 0.988 & 0.991 & 105.3 \\
\hline$W_{2} I$ & 0.988 & 1.002 & 103.7 & 0.988 & 0.999 & 105.1 \\
\hline $\mathrm{W}_{2} \mathrm{II}$ & 0.987 & 0.990 & 103.4 & 0.987 & 0.996 & 105.2 \\
\hline$W_{3} I$ & 0.996 & 0.985 & 107.3 & 0.990 & 0.985 & 105.3 \\
\hline$W_{3} I I$ & 0.992 & 0.994 & 105.3 & 0.988 & 0.992 & 105.2 \\
\hline $\mathrm{W}_{4} \mathrm{I}$ & 0.992 & 0.987 & 102.8 & 0.988 & 0.984 & 103.6 \\
\hline $\mathrm{W}_{4 \mathrm{~A}} \mathrm{II}$ & 0.992 & 0.981 & 104.0 & 0.985 & 0.987 & 104.4 \\
\hline \multirow[t]{2}{*}{$\mathrm{W}_{5} \mathrm{I}$} & 0.997 & 0.987 & 103.2 & 0.994 & 0.986 & 103.5 \\
\hline & & $8.8 \mathrm{GPa}$ & & & & \\
\hline$W_{1} I$ & 1.014 & 0.986 & 100.8 & & & \\
\hline$W_{1} I I$ & 0.983 & 0.990 & 105.5 & & & \\
\hline$W_{2} I$ & 0.991 & 1.006 & 106.0 & & & \\
\hline $\mathrm{W}_{2} \mathrm{II}$ & 0.986 & 0.999 & 104.9 & & & \\
\hline $\mathrm{W}_{3} \mathrm{I}$ & 0.991 & 0.985 & 104.7 & & & \\
\hline $\mathrm{W}_{3} \mathrm{ll}$ & 0.987 & 0.990 & 105.2 & & & \\
\hline $\mathrm{W}_{4} \mathrm{I}$ & 0.990 & 0.981 & 104.0 & & & \\
\hline $\mathrm{W}_{4 \mathrm{~A}} \mathrm{ll}$ & 0.984 & 0.989 & 105.5 & & & \\
\hline$W_{5} I$ & 0.991 & 0.986 & 105.7 & & & \\
\hline
\end{tabular}


at $3.2 \AA$ is mainly due to the $\mathrm{Al}_{2}-\mathrm{Si}_{5}$ distances, and indicates that a significant deformation of the 4-ring has occurred; namely, the $\mathrm{O}_{8}-\mathrm{O}_{9}$ distance, which is approximately parallel to $\mathbf{c}$ and is shorter than the $\mathrm{O}_{5}-\mathrm{O}_{14}$ distance at $P_{\text {amb }}$, becomes larger than $\mathrm{O}_{5}-\mathrm{O}_{14}$ as an effect of pressure.

The described response of yugawaralite to pressure is actually governed by the presence of the extra-framework species that act as templates in driving the framework deformations. Such template effects may be appreciated by inspecting Figures $3 \mathrm{c}$ and d. Due to electrostatics, $\mathrm{Ca}$ is close to $\mathrm{O}$ atoms linked to $\mathrm{Al}$, therefore the $\mathrm{Ca}-\mathrm{Al}$ distances can be considered optimal, and indeed only high pressures $(P \geq 6.3 \mathrm{GPa}$, i.e., after the second discontinuity in the $V / P$ experimental plot) are capable of shortening such distances in a discontinuous way. In the $\mathrm{Ca}-\mathrm{Si}$ $g(r)$ values, however, such an effect is evident even at moderate pressures, with $\mathrm{Ca}-\mathrm{Si}$ distances that decrease continuously with volume contraction. This implies that $\mathrm{SiO}_{4}$ tetrahedra, via $P$-induced T-O-T angle deformations, get closer to $\mathrm{Ca}$ without evident discontinuity. The yugawaralite framework is therefore responding to pressure by rearranging its tetrahedra around $\mathrm{Ca}$ to reduce the free spaces in the channels.

The water system. The calculated $\mathrm{H}-\mathrm{O}_{\text {frame }}$ and $\mathrm{H}-\mathrm{O}_{\text {water }} g(r)$ values are shown in Figures 3 e-f. We first noticed that the water system undergoes significant structural changes in passing from the moderate pressure regime $(P \leq 3.9 \mathrm{GPa})$ to higher pressures $(P \geq 6.3 \mathrm{GPa})$. In particular, the $\mathrm{H}-\mathrm{O}_{\text {water }} g(r)$ curve becomes less distinct in the 1.5-2.4 $\AA$ range, i.e., in the region corresponding to water-water hydrogen bonds; the peak at $\sim 1.75 \AA$ found at moderate pressures broadens significantly for $P \geq 6.3 \mathrm{GPa}$. Moreover, the $\mathrm{H}-\mathrm{O}_{\text {frame }} g(r)$ curves calculated for $P \geq 6.3 \mathrm{GPa}$ show a new peak at about $2.5 \AA$, i.e., in a region corresponding to a minimum at lower pressures.

On the whole, these results indicate that structural modifications in the hydrogen bonding network occur in correspondence with the second discontinuity in the experimental $V / P$ curve (Arletti et al. 2003). At $P \leq 3.9 \mathrm{GPa}$ the $g(r)$ values indicate strong inter-water hydrogen bonds, whereas at higher pressures a larger number of framework $\mathrm{O}$ atoms are found at hydrogenbonding distances from water hydrogen atoms, thus weakening, on average, the inter-water interactions. This result corresponds with that found for the water molecules in bikitaite at high- $P$ (Ferro et al. 2002), where volume contractions caused stronger water-framework interactions.

\section{Influence of the occupancy of the $W_{5}$ site on the high- $P$-induced deformations}

In this section the $P$-induced deformations of UNIT I and II are compared. As mentioned above, the simulation system YU9W is characterized by a $50 \%$ occupancy of the $\mathrm{W}_{5}$ site, i.e., a water molecule occupies this site in UNIT I whereas in UNIT II the $\mathrm{W}_{5}$ site is empty.

In general, the framework geometrical parameters calculated for the two distinct units of the YU9W system, for instance the T-O-T angles (Table 4) and the $\mathrm{O}_{8}-\mathrm{O}_{9}$ and $\mathrm{O}_{5}-\mathrm{O}_{14}$ distances (Fig. 5), may show very different $P$ responses. The reason why these $P$-induced deformations are different in UNITs I and II should be looked for in the different hydrogen bonding network formed by water molecules according to the presence/absence of a molecule

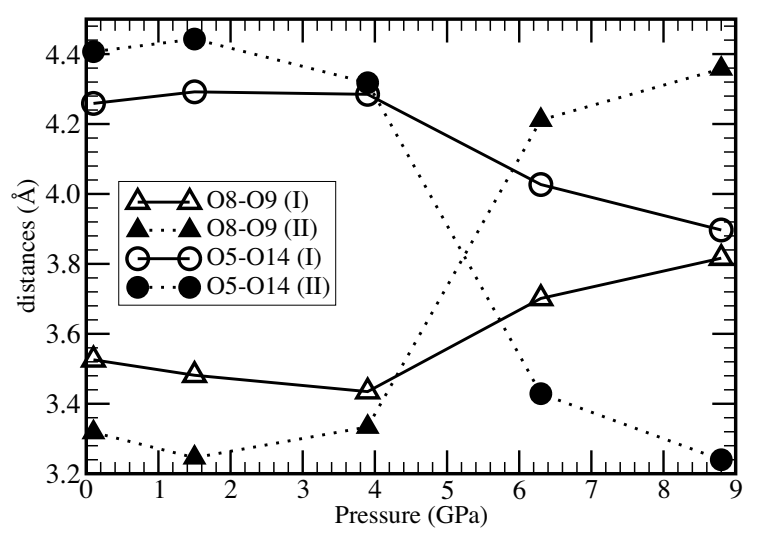

FIGURE 5. $\mathrm{O}_{8}-\mathrm{O}_{9}$ and $\mathrm{O}_{5}-\mathrm{O}_{14}$ distances in UNIT I and UNIT II as a function of pressure.

at the $\mathrm{W}_{5}$ site. Indeed, in UNIT I the water molecule $\mathrm{W}_{5}$ forms a strong hydrogen bond with $\mathrm{W}_{1}$, whereas when $\mathrm{W}_{5}$ is absent (UNIT II), $\mathrm{W}_{1}$ is no longer involved in this inter-water hydrogen bond and can therefore interact more strongly with the framework $\mathrm{O}$ atoms (see Table 5 and Fig. 2). Similarly, $\mathrm{W}_{3}$ forms stronger hydrogen bonds with framework $\mathrm{O}$ atoms in UNIT II than in UNIT I. Such stronger water-framework interactions seem to be correlated to the different deformations of UNIT II found in our simulations.

The behavior of the water molecules is far from simple, as small $P$-induced changes in cell parameters lead to rearrangements in the hydrogen bond network. Only the $\mathrm{W}_{2}$ water has been found linked to the same hydrogen bond partners $\left(\mathrm{O}_{6}\right.$ and $\left.\mathrm{O}_{15}\right)$ in both units and at all pressures; the $\mathrm{W}_{2} \mathrm{II}$ molecule becomes hydrogen bonded to a third framework oxygen, $\mathrm{O}_{6} \mathrm{II}$, at $6.3 \mathrm{GPa}$. A possible explanation might be its interaction with a framework oxygen bonded to an $\mathrm{Al}\left(\mathrm{O}_{15}\right)$ atom, which is less saturated than framework $\mathrm{O}$ atoms linked to $\mathrm{Si}$ atoms only, and therefore leads to the formation of a very strong and stable hydrogen bond. The high- $P$ behavior of $\mathrm{W}_{2}$ is also in line with the results of dehydration experiments on yugawaralite (Alberti et. al 1996). At high temperature, $\mathrm{W}_{2}$ is one of the most stable water molecules, so that its loosing at $200{ }^{\circ} \mathrm{C}$ causes the structure collapses.

With increasing pressure the other molecules change by rotating either the type or the number of partners, also showing equilibrium among different arrangements within the same trajectory. This indicates that there are moderate energy differences between the diverse structures sampled by the room temperature simulations. Moreover, the activation energies for the inter-conversion of one arrangement to another one should be small, typically of the order of $k T$.

The bond distances and angles of the nine water molecules are reported in Table 6. In general, applied pressure does not significantly affect the molecular geometry of water, with the exception of $\mathrm{W}_{1}$ in UNIT I. Such a water molecule at $P \geq 6.3 \mathrm{GPa}$ shows the smallest $\mathrm{HOH}$ angle $\left(\sim 101^{\circ}\right.$, see Table 6$)$, whereas the $\mathrm{W}_{1}$ bond angle in UNIT II is larger than the ideal value of $104.5^{\circ}$. This may be related to the number of hydrogen bonds involving $\mathrm{W}_{1} \mathrm{I}$ at high- $P$ : two very strong (as proton donor) with $\mathrm{W}_{5}$ and $\mathrm{O}_{16}$ and a weaker one (as proton acceptor) with $\mathrm{W}_{3}$, which is missing at lower pressure (see Table 5). The other $\mathrm{W}_{1}$ molecule $\left(\mathrm{W}_{1} \mathrm{II}\right)$ 
forms weaker hydrogen bonds and only with framework $\mathrm{O}$ atoms. Interestingly, the hydrogen bonds formed by $\mathrm{W}_{1}$ in UNIT I and UNIT II are different at all the investigated pressures because $\mathrm{W}_{1} \mathrm{I}$ is always hydrogen bonded to $\mathrm{W}_{5}$.

Moreover, the occupancy of the $\mathrm{W}_{5}$ site affects the hydrogen bond network formed by the water molecules not directly interacting with $\mathrm{W}_{5}$ as well. For instance, both $\mathrm{W}_{3}$ and $\mathrm{W}_{4}$ show a very different behavior as a function of pressure in the two units (see Table 5). At moderate pressure, $\mathrm{W}_{3}$ and $\mathrm{W}_{4}$ are hydrogen bonded to each other both in UNIT I and in UNIT II, however $\mathrm{W}_{3}$ acts as a proton donor and $\mathrm{W}_{4}$ as a proton acceptor in UNIT I, whereas the opposite is found in UNIT II. Above the second $V / P$ discontinuity $(P>6.3 \mathrm{GPa}), \mathrm{W}_{3}$ and $\mathrm{W}_{4}$ in both units are no longer linked to each other. However, they are still different in the two units: $\mathrm{W}_{3} \mathrm{I}$ becomes hydrogen-bonded to $\mathrm{W}_{1} \mathrm{I}$ and weakly to $\mathrm{O}_{11}$, whereas $\mathrm{W}_{3} \mathrm{II}$ is strongly linked to $\mathrm{O}_{8}$ and weakly bonded with $\mathrm{O}_{11}$ and $\mathrm{O}_{15}$.

To understand whether the chemical environment (e.g., the nearest neighbor atoms) may significantly affect the physical properties of the water molecules as well, we have calculated the dipole moment of the water molecules (Silvestrelli and Parrinello 1999). We have chosen some configurations selected along the $P_{\text {amb }}$ and $8.8 \mathrm{GPa}$ trajectories. The average dipole moment $\langle\mu>$ of water in yugawaralite at $P_{\mathrm{amb}}$ is $3.02 \mathrm{D}$, whereas at $8.8 \mathrm{GPa}$ it is $3.17 \mathrm{D}$. No clear correlation has been found between the value of the dipole moment of the individual water molecules and their environments. All molecules have a calculated dipole moment in line with the values typical of water in the condensed phase $(\mu \sim 3 \mathrm{D})$. It is interesting to notice that the $\mathrm{W}_{5}$ dipole moment is very close to $\langle\mu\rangle$, and thus is not different from those of the other water molecules that are Ca-coordinated. However, such polarization can be ascribed to the hydrogen bond network involving $\mathrm{W}_{5}$.

As the occupancy of the $\mathrm{W}_{5}$ site influences the behavior of the whole water system, it follows as well that the Ca coordination polyhedron should be affected, even though the $\mathrm{Ca}$ atom is never coordinated to the water molecule at $\mathrm{W}_{5}$. The average coordination distances of $\mathrm{Ca}$ in UNITs I and II with both framework and water $\mathrm{O}$ atoms are slightly different in the whole pressure range (Table $3 b$ ). For instance, at moderate applied pressures the $\mathrm{Ca}-\mathrm{O}_{9}$ distance is significantly larger in UNIT II than in UNIT $\mathrm{I}$, and the same happens for the $\mathrm{Ca}-\mathrm{W}_{3}$ and $\mathrm{Ca}-\mathrm{W}_{2}$ distances. In general, the radius of the coordination shell of $\mathrm{Ca}$ in UNIT I is always shorter than in UNIT II, owing to the $\mathrm{W}_{5}$ water molecule, which forces a more compact arrangement of the Ca coordination polyhedron. It is also worth noticing that the $\mathrm{Ca}-\mathrm{W}_{2}$ distance in UNIT II - where $\mathrm{W}_{5}$ is absent - becomes larger with increasing pressure and at $8.8 \mathrm{GPa}$ is $\sim 0.2 \AA$ larger than the average coordination distance.

\section{The binding energy of $W_{5}$}

The results presented up to now unambiguously show that the presence of a certain amount of water at the $\mathrm{W}_{5}$ site in yugawaralite affects the coordination shell of the extra-framework cation at a microscopic level, and the hydrogen bonding network and their response to pressure as well. Moreover, different local distortions of the framework structure also occur. It would be interesting, therefore, to investigate the energetic stability of $\mathrm{W}_{5}$ as a function of increasing pressure.

For each set of cell parameters obtained from XRPD, the binding energy of $\mathrm{W}_{5}$ was calculated by subtracting from the minimum energy of YU9W the sum of the minimum energies of a system (YU8W) containing 8 water molecules per unit cell (with zero occupancy of $\mathrm{W}_{5}$ ), and of an isolated water molecule in the same simulation cell. The energy minimum for each system was obtained by optimizing the energy vs. the atomic positions until the forces on each atom were less than $1 \times 10^{-4}$ atomic units.

The computational parameters adopted in this new set of calculations (i.e., energy cutoff and gradient functional approximations) were the same used for the previously discussed MD simulations. For each point in the V/P curve, the energy difference $\Delta E=E_{\mathrm{YU} 9 \mathrm{~W}}-\left(E_{\mathrm{YU} U \mathrm{~W}}+E_{\mathrm{W} 5}\right)$ was calculated and reported in Figure 6. Remarkably, $\Delta E$ is negative at low pressures and becomes positive for $P>2.5 \mathrm{GPa}$, indicating that the binding energy of $\mathrm{W}_{5}$ in yugawaralite decreases with pressure. This fact is not surprising when considering that the yugawaralite volume contraction in the $P_{\text {amb }}-8.8 \mathrm{GPa}$ range amounts to $125 \AA^{3}$, corresponding to $\sim 4$ times the volume of a water molecule at room conditions in the liquid phase. By increasing pressure, therefore, the presence of $\mathrm{W}_{5}$ might induce energetically unfavorable local structural deformations in the yugawaralite framework.

It should be recalled here that our simulation systems are characterized by a $\mathrm{W}_{5}$ occupancy higher than the experimental one, therefore the effects of $\mathrm{W}_{5}$ might be overemphasized. However, the trend of the calculated energy differences should not be qualitatively modified. We also point out that in the optimization processes, various local minima, characterized by very small energy differences of the order of $k T$ at $300 \mathrm{~K}$ ), were found, thus supporting the idea that at ambient temperature the system may easily jump among different local-minima structures, as previously discussed.

For the cell parameters corresponding to the lowest $(8.8$ $\mathrm{GPa})$ and highest $\left(P_{\text {amb }}\right)$ studied volumes we performed room temperature MD simulations for the YU8W system. The main result of such simulations without $\mathrm{W}_{5}$ is that, in passing from $P_{\text {amb }}$ to $8.8 \mathrm{GPa}$, the $P$-induced $\mathrm{O}_{2} \leftrightarrow \mathrm{O}_{3}$ exchange in the $\mathrm{Ca}$

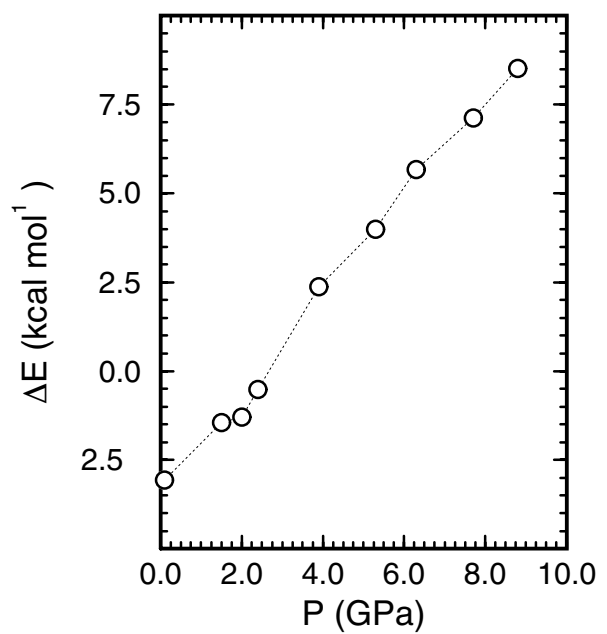

FIGURE 6. Binding energy of a water molecule in the $\mathrm{W}_{5}$ site as a function of pressure. 
polyhedron is observed in the YU8W system as well. Hence, such a transformation, responsible for the discontinuities in the $V / P$ experimental curve, occurs independently of the $W_{5}$ occupancy, is easily understandable by recalling that $\mathrm{W}_{5}$ does not belong to the coordination polyhedron of $\mathrm{Ca}$. However, as discussed above (see, e.g., Fig. 5), even $\mathrm{W}_{5}$ plays a role in the details of the yugawaralite response to pressure. Hence, the influence of $\mathrm{W}_{5}$ on the framework structure further supports the hypothesis of the template effect of the extra-framework species in driving the zeolite framework deformation upon compression

\section{ACKNOWLEDGMENTS}

The European Synchrotron Radiation Facility is kindly acknowledged for allocation of beam-time under proposals no. $\mathrm{CH}-831$ and $\mathrm{CH}-1019$. This work was supported by the Italian MIUR (FIRB: Proprietà ed applicazioni tecnologiche di minerali e loro analoghi di sintesi). The paper benefited from the comments of G.D. Gatta, A. Pawley, and an anonymous referee.

\section{REFERENCES CITED}

Alberti, A., Quartieri, S., and Vezzalini, G. (1994) Structural modifications induced by dehydration in yugawaralite. Studies in Surface Science and Catalysis, 84, 637-644.

- - - (1996) Thermal behavior of zeolites: single crystal X-ray study of dehydration and rehydration mechanism in yugawaralite. European Journal of Mineralogy, 8, 1273-1282.

Alberti, A., Fois, E., and Gamba, A. (2003) A Molecular Dynamics study of the behavior of sodium in low albite. American Mineralogist 88, 1-10.

Arletti, R., Ferro, O., Quartieri, S., Sani, A., Tabacchi, G., and Vezzalini, G. (2003) Structural deformation mechanisms of zeolites under pressure. American Mineralogist, 88, 1416-1422.

Armbruster, T. and Gunter, M.E. (2001) Crystal structures of natural zeolites. In D Bish and D. Ming, Eds., Natural zeolites: occurrences, properties, applications. Reviews in Mineralogy and Geochemistry, 45, 1-67. The Mineralogical Society of America and the Geochemical Society, Washington, D.C.

Baerlocher, Ch., Meier, W.M., and Olson, D.H. (2001) Atlas of zeolite framework types. Fifth Revised Edition, Elsevier, Amsterdam, The Netherlands.

Ballone, P., Quartieri, S., Sani, A., and Vezzalini, G. (2002) High-pressure deformation mechanism in scolecite: a combined computational-experimental study. American Mineralogist, 87, 1194-1206.

Becke, A.D. (1988) Density functional exchange energy approximation with correct asymptotic behavior. Physical Review, A38, 3098-3100.

Car, R. and Parrinello, M. (1985) Unified approach for molecular dynamics and density-functional theory. Physical Review Letters, 55, 2471-2474.

Ceriani, C., Fois, E., Gamba, A., Tabacchi, G., Ferro, O., Quartieri, S., and Vezzalini, G. (2004) Dehydration dynamics of bikitaite: Part II. Ab initio molecular dynamics study. American Mineralogist, 89, 102-109.

Comodi, P., Gatta, G.D., and Zanazzi, P.F. (2001) High-pressure structural behaviour of heulandite. European Journal of Mineralogy, 13, 497-505.

- - - (2002) High-pressure structural behaviour of scolecite. European Journal of Mineralogy, 14, 567-574.

Dove, M.T., Heine, V., and Hammonds, K.D. (1995) Rigid Unit Modes in framework silicates. Mineralogical Magazine, 59, 629-639.
Dove, M.T., Trachenko, K.O., Tucker, M.G., and Keen, D.A. (2000) Rigid Unit Modes in framework structures: Theory, experiment and applications. In S.A.T. Redfern and M.A. Carpenter, Eds., Transformation processes in minerals, 39, 1-33. Reviews in Mineralogy and Geochemistry, Mineralogical Society of America, Washington, D.C.

Ferro, O., Quartieri, S.,Vezzalini, G., Fois, E., Gamba, A., and Tabacchi, G. (2002) High-pressure behavior of bikitaite: an integrated theoretical and experimental approach. American Mineralogist, 87, 1415-1425.

Fois, E., Gamba, A., Tabacchi, G., Quartieri, S., and Vezzalini, G. (2001) On the collective properties of water molecules in one dimensional zeolitic channels. Physical Chemistry Chemical Physics, 3, 4158-4163.

Gatta, D.G., Comodi, P., and Zanazzi, P.F. (2003a) New insights on high-pressure behavior of microporous materials from X-ray single-crystal data. Microporous and Mesoporous Materials, 61, 105-115.

Gatta, D.G., Boffa Ballaran, T., Comodi, P., and Zanazzi, P.F. (2003b) Topological effects on microporous materials under pressure conditions: framework and extra-framework behaviour of $\mathrm{Ca}$ - and $\mathrm{Ba}$-fibrous zeolites. Proceedings of the $33^{\text {rd }}$ National Congress of the Italian Association of Crystallography, Trieste, Italy.

- - - (2004) Isothermal equation of state and compressional behavior of tetragonal edingtonite. Americal Mineralogist, 89, 633-639.

Gillet, P., Malézieux, J.M., and Itiè, J.P. (1996) Phase changes and amorphization of zeolites at high pressures: the case of scolecite and mesolite. American Mineralogist, 81, 651-657.

Hammonds, K.D., Deng, H., Heine, V., and Dove, M.T. (1997) How floppy modes give rise to adsorption sites in zeolites. Physical Review Letters, 78, 3701-3704

Hammonds, K.D., Heine, V., and Dove, M.T. (1998) Rigid-Unit Modes and the quantitative determination of the flexibility possessed by zeolite frameworks. Journal of Physical Chemistry B, 102, 1759-1767.

Huang, Y. and Havenga, E.A. (2001) Why do zeolites with LTA structure undergo reversible amorphization under pressure? Chemical Physics Letters, 345, 65-71.

Hutter, J., Parrinello, M. et al. (1990-2001) Computer code CPMD V3.5, http: //www.cpmd.org. IBM Research, Zurich.

Kleinmann, L. and Bylander, D.M. (1982) Efficaceus form for model pseudopotentials. Physical Review Letters, 48, 1425-1428.

Kohn, W. and Sham, L.J. (1965) Self-consistent equations including exchange and correlation effects. Physical Review, A140, 1135-1141.

Kvick, Å., Artioli, G., and Smith, J.V. (1986) Neutron diffraction study of the zeolite yugawaralite at $13 \mathrm{~K}$. Zeitschrift für Kristallographie, 174, 265-281.

Lee, Y., Hriljac, J.A., Vogt, T., Parise, J.B., Edmondson, M.J., Anderson, P.A., Corbin, D.R., and Takaya, N. (2001) Phase transition of zeolite RHO at high-pressure. Journal of American Chemical Society, 123, 8418-8419.

Nosé, S. (1984) A unified formulation of the constant temperature molecular dynamics methods. Journal of Chemical Physics, 81, 511-519.

Perdew, J.P. (1986) Density-functional approximation to the correlation energy of the inhomogeneus electron gas. Physical Review B, 33, 8822-8824.

Silvestrelli, P.L. and Parrinello, M. (1999) Water molecule dipole in the gas and in the liquid phase. Physical Review Letters, 82, 3308-3311.

Troullier, N. and Martins, J.L. (1991) Efficient pseudopotentials for plane-wave calculations. Physical Review B, 43, 1993-2006.

Tse, J.S. and Klug, D.D. (1992) Structural memory in pressure-amorphized $\mathrm{AlPO}_{4}$ Science, 255, 1559-1561.

MANUSCRIPT RECEIVED MARCH 23, 2004

MANUSCRIPT ACCEPTED MAY 11, 2004

MANUSCRIPT HANDLED BY ALISON PAWLEY 